ISSN 0719-7160

\title{
EL SENTIDO RELIGIOSO DE LA VIDA Aportes al debate constitucional
}

\author{
[The religious sense of life]
}

\author{
JOAQUÍN SILVA SOLER ${ }^{1}$
}

\begin{abstract}
Resumen
En los últimos años Chile ha vivido procesos sociales y políticos de gran importancia. Entre ellos destaca el estallido social del año 2019 y el plebiscito del año 2020 en el que el 78\% de los votantes expresó su acuerdo a la redacción de una nueva constitución, y a que esta fuera elaborada por una Convención Constituyente elegida especialmente para estos efectos. En los próximos años, el futuro de Chile estará en gran parte condicionado por este proceso constituyente y por la nueva Constitución que resulte de él. Entre las tantas cuestiones que serán objeto de diálogo y deliberación está la pregunta por el lugar de la religión en la nueva constitución. Al respecto, este artículo propone una reflexión de una cuestión antecedente a las definiciones jurídico-constitucionales; a saber, una reflexión sobre la cuestión del sentido religioso de la vida. Sin esta reflexión, la deliberación se podría circunscribir a la incorporación, o no, de determinados derechos, como la libertad religiosa, de culto y de educación, entre otros, sin atender antes a las razones por las cuales dicha discusión es importante en el proceso constituyente. Después de una introducción, el artículo propone pensar la religión en cinco niveles distintos: la religión en su dimensión existencial; la religión en su dimensión antropológica; la religión como dimensión trascendental; la religión en su dimensión política; y, finalmente, una consideración de la religión en su dimensión estratégica. Para concluir, el artículo deriva algunas consecuencias de la atención a estas cinco dimensiones del sentido religioso de la vida.
\end{abstract}

Palabras claves: religión, religiosidad, espiritualidad, sentido religioso, antropología.

\begin{abstract}
In recent years Chile has experienced social and political processes of great importance. Among them is the social outburst of 2019 and the plebiscite of 2020 in which 78\% of voters agreed to the drafting of a new constitution, and to have it drawn up by a Constituent Convention specially elected for this purpose. In the coming years, Chile's future will be largely conditioned by this constituent process and the new Constitution that results from it. Among the many issues that will be the subject of dialogue and deliberation is the question of the place of religion in the new constitution. In this regard, this article proposes a reflection of an issue preceding legal-constitutional definitions; namely a reflection on the question of the religious meaning of life. Without this reflection, deliberation could be limited to the incorporation, or not, of certain rights, such as religious freedom, worship and education, among others, without first addressing the reasons why such discussion is important in the constituent process. After an introduction, the article proposes to think of religion at five different levels: religion in its existential dimension; religion in its anthropological dimension; religion as a transcendental dimension; religion in its political dimension; and, finally, a consideration of religion in its strategic dimension. In conclusion, the article derives some consequences from attention to these five dimensions of the religious sense of life.
\end{abstract}

\footnotetext{
${ }^{1}$ Doctor en Teología, Profesor Titular de la Facultad de Teología de la Pontificia Universidad Católica de chile. Email: jsilvas@uc.cl
} 
Joaquín Silva Soler: El sentido religioso de la vida

Keywords: religion, religiosity, spirituality, religious sense, anthropology.

DOI: 10.7764/RLDR.11.138 


\section{INTRODUCCIÓN}

Al ser humano se le puede comprender desde distintas lógicas: desde teorías histórico-evolutivas como homo sapiens; desde la filosofía, se le reconoce por el lógos, como un ser racional (desde Heráclito); desde la política, como animal político (Aristóteles); desde la economía, como homo economicus, (John Stuart Mill), y desde diversos lógos y saberes, también como un ser religioso. En el Catecismo de la Iglesia católica leemos: "De múltiples maneras, en su historia, y hasta el día de hoy, los hombres han expresado su búsqueda de Dios por medio de sus creencias y sus comportamientos religiosos (oraciones, sacrificios, cultos, meditaciones, etc.). A pesar de las ambigüedades que pueden entrañar, estas formas de expresión son tan universales que se puede llamar al hombre un ser religioso" (n.28) (Cf Enders, 2007). Si esto es así, que las personas y las culturas han recurrido hasta hoy a las religiones para comprenderse a sí mismas, para comprender el mundo, para relacionarse entre sí, para darle sentido a su existencia, entonces sería un despropósito dejar las religiones fuera del debate constitucional.

Para comprender el carácter religioso de nuestra humanidad, quisiera comenzar recordando a nuestra gran poeta Gabriela Mistral, quien el año 1922 justamente escribió un texto que tituló "El sentido religioso de la vida". ¿Qué constituye, por ejemplo, el que un artista sea religioso?, preguntaba Gabriela Mistral. Y responde diciendo que "entre los artistas son religiosos los que, fuera de la capacidad para crear, tienen al mirar el mundo exterior la intuición del misterio, y saben que la rosa es algo mas que una rosa y la montaña algo mas que una montaña; ven el sentido místico de la belleza y hallan en las suavidades de las hierbas y de las nubes del verano la insinuación de una mayor suavidad, que está en las yemas de Dios"(Mistral, 2020, p. 27). Esa experiencia de lo infinito en la finitud del mundo es religión. El artista no es religioso por producir objetos religiosos, sino cuando es capaz de desentrañar la vida infinita que está en la materia y en el espíritu humano. 
Me parece que esta es una pista muy importante para comprender tanto la religión como la vida. La vida puede tener en los individuos y en las culturas diversos sentidos y uno de ellos puede ser el religioso. B.Welte, comprende la religión como "aquella forma de existencia en la que las personas se sienten determinadas por aquella realidad que llamamos Dios, o más ampliamente lo divino" (Welte, 1982, p. 31). Efectivamente, la religión es una forma de existencia, entre otras. ¿Y qué es lo propio de esta forma de existencia? El vivirla en relación a lo divino; es reconocer y vivir el sentido religioso del cual está preñada la existencia entera. Religión, por tanto, no designa una realidad distinta a la vida, ni la vida una dimensión distinta a la religión. Cuando la vida es vivida en sintonía con el misterio, entonces se vuelve religiosa.

\section{LA RELIGIÓN COMO RESPUESTA A LAS PREGUNTAS QUE INQUIETAN AL SER HUMANO}

Aquello que observamos de las religiones son principalmente sus doctrinas, símbolos y ritos; pero esto que observamos no se explica por sí mismo, sino que está asociado a algo que no observamos inmediatamente o que, quizás no queremos observar, y que son las cuestiones que inquietan profundamente la conciencia humana a través de los siglos: por qué el ser y no la nada; cuál el sentido no sólo de esto o de aquello, sino del todo; que nos sucede en la muerte y después de ella; cómo enfrentamos la muerte, también como "negación determinada" (Hegel), la fragilidad y caducidad de nuestros proyectos y realizaciones más queridas, etc. Estas cuestiones, entre otras muchas, han llevado a los hombres y mujeres de todos los tiempos a postular la existencia de dioses, un Dios, una realidad trascendente, un espíritu absoluto. Como afirma Grondin, "la religión propone las respuestas más fuertes, antiguas y vivas a la cuestión del sentido de la vida" (Grondin, 2010, p. 13). Más ampliamente, el Concilio Vaticano II afirma que "Los hombres esperan de las 
diversas religiones la respuesta a los enigmas recónditos de la condición humana, que hoy como ayer, conmueven íntimamente su corazón: ¿Qué es el hombre, cuál es el sentido y el fin de nuestra vida, el bien y el pecado, el origen y el fin del dolor, el camino para conseguir la verdadera felicidad, la muerte, el juicio, la sanción después de la muerte? ¿Cuál es, finalmente, aquel último e inefable misterio que envuelve nuestra existencia, del cual procedemos y hacia donde nos dirigimos?" (NA 1).

Se podrían distinguir tres tipos de respuestas a esta pregunta por el sentido y, en general, a las preguntas más radicales de la existencia humana: 1) las respuestas religiosas y espirituales, que son las que han prevalecido en la historia de las humanidad, y en las diferentes culturas; 2 ) las respuestas laicas, más recientes, que sin rechazar necesariamente la existencia de una trascendencia, apuestan a la bondad humana, sea de un modo más utópico y humanista, o de un modo más hedonista e individual; en ambos casos se puede reconocer una forma encubierta de religión: la justicia, la igualdad, el placer, el consumo y otras aspiraciones semejantes son las que movilizan la existencia, le dan un horizonte, un valor; y 3) hay respuestas que afirman que la vida no tiene sentido, rechazando más o menos explícitamente un sentido religioso o trascendente.

Uno de los teólogos más relevantes del siglo pasado, Karl Rahner (1904-1984), reconoce en el preguntar del ser humano no sólo la tensión entre finitud e infinitud, sino que en esa misma tensión la experiencia de ser espíritu, de estar abierto a una realización siempre más plena. En efecto, escribe Ranher: el ser humano "en cuánto experimenta radicalmente su finitud, Ilega más allá de esa finitud, se experimenta como espíritu. El horizonte infinito del preguntar humano se experimenta como un horizonte que retrocede cada vez más lejos, cuanto más respuestas somos capaces de darnos. El hombre puede intentar dejar en paz la terrible infinitud a la que está expuesto al preguntar, por la angustia ante lo terrible puedo ir a lo familiar y cotidiano; pero la infinitud en la que se hayan marcado penetra también su acción cotidiana. En principio, el hombre está siempre en camino"(Rahner, 1989, p. 51). 
Como agudamente reconoce Gabriela Mistral, podemos vivir de una forma no religiosa, pero - quizás - nos podría parecer "baldío y despreciable el día en que únicamente cumplimos el escueto deber material de procurarnos el alimento y no tuvimos una emoción de índole elevada y no la alimentamos con el agua viva de un canto, con el perfume de un trozo bello de lectura, con la piedad hacia el dolor que se nos cruzó en el camino: hemos olvidado en tal día la presencia del alma"(Mistral, 2020, p. 25).

En un sentido semejante el teólogo judío Ephraim Elimelech Urbach afirma que: "gran parte de la historia de las religiones, y entre ellas la historia de la religión de Israel, es la descripción de la búsqueda de una solución que permita tender un puente por sobre el abismo infranqueable. Precisamente, el alejamiento total de toda característica o cualidad antropomórfico en la concepción de Dios conlleva a llenar un abismo mediante un elemento intermedio"(En: Skorka, 2006, p. 483).

\section{LA EXISTENCIA VUELTA HACIA AQUELLO QUE NOS CONCIERNE INCONDICIONADAMENTE}

Existe un abismo infranqueable entre Dios y el hombre. La cercanía de Dios es siempre al modo de Dios, una cercanía trascendente. Dios permanece siendo lo indisponible para el hombre. Las religiones, en sus mejores versiones, integran dinámicamente ambas afirmaciones: la trascendencia y la cercanía de Dios. El filósofo y teólogo alemán Bernhard Welte, ha sido quizás uno de los pensadores que más agudamente ha pensado al ser humano en esta tensión entre finitud e infinitud (Cf. Welte, 1973), en cómo la existencia humana se desenvuelve siempre en coordenadas interés, futuro y apuesta; cómo en la misma vida personal y social pueden las personas abrirse a un sentido último y trascendente (Cf. Welte, 1982). 
Por tanto, cuando decimos que la religión es una "forma de existencia", o que la vida tiene un "sentido religioso", con ello no queremos nivelar la experiencia de la cercanía trascendente de Dios con las demás formas de existencia o con los demás sentidos de la vida. Como expresa un gran teólogo protestante, Paul Tillich: "Si la revelación es la irrupción de lo Incondicional en el mundo de lo condicionado, no puede dejar que se la condicione, convirtiéndola en una esfera junto a otras esferas, la religión al lado con la cultura"(Tillich, 1973, p. 10). La religión, según Tillich, "Está dirigida hacia el significado incondicionado, hacia la sustancia del significado... hacia el Incondicional" (Tillich, 1973, p. 44). El núcleo de la religión está dado por aquello que nos "concierne incondicionalmente" (ultimate concern) (Tillich, 1982, p. 26). Aquello que "nos concierne incondicionalmente", no es otra cosa, explica el mismo Tillich- que la "traducción abstracta del gran mandamiento: El señor, nuestro Dios, es el único señor, y amarás al señor, tu Dios, con todo tu corazón, con toda tu alma, con toda tu mente y con toda tu fuerza" (Mc 12,29-30). La vida religiosa no es una vida al lado de otras vidas posibles: artísticas, ciudadana, intelectual, deportiva, etc. La vida es religiosa cuando es vivida de cara al sentido último e incondicionado de la existencia, cuando ella se deja transformar por este sentido incondicionado, cuando se orienta toda ella a lo último e incondicionado.

La idea de la religión como "preocupación última por lo que constituye el fondo y el sentido de nuestro ser" es cercana, como lo reconoce el mismo Tillich a la idea de Schleirmacher de la religión como el "sentimiento de la absoluta dependencia". En efecto, "el "sentimiento" significa la conciencia inmediata de algo incondicional, en el sentido de la tradición agustiniana y franciscana [...] Y, en la definición de Schleiermacher, "dependencia" era, a nivel cristiano, una dependencia "teleológica" -es decir, una dependencia de carácter moral, una dependencia que implica la libertad y excluye toda interpretación panteísta y determinista de la experiencia de lo incondicional (Tillich, 1982, p. 63). 


\section{LA RELIGIÓN COMO AFIRMACIÓN DEL CARÁCTER TRASCENDENTAL DE LA PERSONA HUMANA}

Pienso que cuando hablamos de Religión, también en un contexto constitucional, lo que está en juego es el reconocimiento del carácter trascendental del ser humano y del carácter trascendental del ejercicio de la libertad. Es cierto, se puede vivir "haciendo-como$\mathrm{si}^{\prime \prime}$ esta apertura trascendental del hombre no existiera, pero muy pronto esos esfuerzos se muestran insatisfactorios, acrecientan aún más nuestra ansiedad y nuestro vacío. También se puede directamente negar esta trascendentalidad de la experiencia humana; sin embargo, la negación teórica no es capaz de negar la existencia real: la condición humana seguirá preguntando, seguirá abierta a lo infinito, podrá indagar si esa tal negación es una respuesta real a la existencia personal, a los anhelos y búsquedas que inquietan el propio pensar y que emergen desde nuestro centro más vital, desde el alma, desde el corazón. Como lo expresa el filósofo Jean Grondin: "no se puede asignar una orientación a la vida si no se reconoce que está suspendida de una esperanza, de un riesgo, aunque un bello riesgo, a saber, el de una vida que vive de tal modo en el sentido que ella misma se trasciende. Y es que el sentido siempre es eso: una dirección, una tensión centrífuga de la conciencia, esa que me hace pasar de una palabra a otra, que me arrastra hacia un destino lejano, hacia un sabor que me atrae pero que nunca llegaría apresar. El sentido sólo está allí dónde somos atrapados, atraídos, transportados fuera de nosotros mismos"(Grondin, 2005, pp. 153-154).

Por lo dicho podemos comprender mejor por qué en la experiencia religiosa lo que está en juego - definitivamente- es la salvación. Karl Rahner, dirá que la salvación no debe entenderse, al menos a priori, "cómo una situación futura que se precipita sorprendentemente sobre el hombre desde fuera a manera de una cosa, ya en forma agradable, ya en forma desagradable, cuando se trata de la perdición, o que se le atribuye en virtud de un juicio moral" (Rahner, 1989, p. 60). La salvación debe comprenderse como la realidad humana, la historia personal y social, transformada por la experiencia de la cercanía 
misericordiosa - amorosa - providente - liberadora de la divinidad, de Dios. La salvación acontece cuando la finitud personal y social es experimentada en su apertura a lo infinito, cuando se reconoce que la muerte no es el destino de cuanto es. La salvación es una existencia reconciliada consigo mismo, con los demás, con nuestro medio ambiente y, por ello, es también existencia reconciliada con Dios.

El sentido religioso de la vida, por tanto, implica una doble afirmación: la de Dios, pero también la del hombre. Muchas veces se ha planteado la afirmación del hombre en oposición a Dios. Con Nietzsche, podemos preguntar: ¿por qué Dios ha muerto? Porque nosotros lo hemos matado. ¿Y por qué lo hemos matado? Porque resultaba un estorbo para la realización plena del hombre. La pregunta que las religiones se deben hacer es si el Dios que proclaman es efectivamente un estorbo a sus aspiraciones de ser, de crear, de gozar, pensar, de ser libre de toda forma de dominio y poder. Pienso que muchas veces hemos planteado la afirmación de Dios en desmedro de la afirmación del hombre. ¿Pero qué Dios es ese que no permite la autonomía y libertad? ¿Qué Dios es aquel que suprime el pensar y el crear? ¿Qué Dios es aquel busca la sumisión y la esclavitud?. Puede que sea una caricatura de Dios o, más probablemente aún un fetiche, es decir una creación nuestra para afirmar bajo la forma de religión la propia voluntad de poder. Como sea, sólo tres testimonios en el Nuevo Testamento que, a mi juicio, son indicativos de cómo la afirmación de Dios es a la vez la afirmación del hombre y, más aún cómo, la afirmación de Dios permite la realización plena del hombre: "no los llamo siervos, sino amigos" (Jn 15,15); "He venido para que tengan vida y la tengan en abundancia" (Jn 10,10); para la libertad nos liberó Cristo (Gál 5,1).

\section{LA RELIGIÓN ES POLÍTICA}

Y si la religión tiene que ver con la salvación y ésta con una existencia reconciliada, que es fuente de alegría y paz, entonces sobre la religión recae una tremenda hipoteca social y política. La religión no es aquello que acontece solamente en el ámbito de la conciencia 
individual o de las prácticas que las personas realizan en un tiempo y espacio de carácter privados. La religión es política o no es religión. Una religión relegada al ámbito de lo privado dejaría de ser propiamente religión porque ya dejaría de afectar a la persona en su existencia real, puesto que ésta es siempre trascendental, es siempre en-sí pero para los demás, en una apertura trascendental a los otros y a Dios. La idea de una religiosidad recluida al ámbito privado es una mera quimera, puesto que nada auténticamente humano se deja reducir a espacios estancos. Nuestra existencia no es nunca sólo personal, ni sólo social, ni sólo económica, o sólo política, o sólo estética. La realidad humana es un entramado de relaciones vitales, dinámicas y, además, muchas veces misteriosas. Para efectos metódicos quizás convengan las determinaciones objetuales de las diversas ciencias, pero la realidad nunca se deja determinar por el conocimiento científico-tecnológico. La religión, la experiencia de salvación que los hombres y mujeres pueden hacer en ella, precisamente mantiene viva esa integridad trascendental de la existencia humana, la unidad de todas las diferencias, la convicción de que cuanto es está tensionado a un futuro en el que serán nuevas todas las cosas (cf Ap 21,5). Así, la religión es política por cuanto no comporta una fuga mundi, sino la transformación de la historia según el querer Dios, según la esperanza de que "todo cuanto ha sido sembrado bajo el signo de la debilidad y de la corrupción será revestido de incorruptibilidad" (GS 39).

La legitimación social y política de la religión es, por cierto, una cuestión histórica, algo que las sociedades y culturas determinan según las condiciones de cada época. Esta legitimación es sin duda importante, por el carácter comunicativo que comporta la salvación. Una religión no es salvífica por la mera declaración de sus representantes, ni siquiera por la buena voluntad de sus miembros. La religión es salvífica cuando resulta significativa para los hombres y mujeres de un tiempo y de un espacio determinado, cuando las personas reconocen en determinados hechos y palabras la irrupción del misterio santo en sus vidas, cuando aquello que es anunciado es acogido según las condiciones y posibilidades de la propia existencia. Sin embargo, esta validación de la religión no está, simplemente, determinada por la demanda, sino que es inherente a la oferta; la religión se desacredita a sí 
misma cuando pierde este carácter social y político, cuando se vuelve en una introspección narcisista que se solaza en la contemplación de sí misma y de las propias obras. Como todo narcisismo, este religioso también está destinado a la muerte. La religión es salir de sí para encontrarse con aquel Otro Absoluto que es Dios, pero un Otro Absoluto que, de un modo desconcertante -y quizás también escandaloso- para nosotros, se ha querido identificar con los otros que son mis hermanas y hermanos, especialmente los más pobres: "Les aseguro que todo lo que hayan hecho en favor del más pequeño de mis hermanos, a mí me lo han hecho" (Mt 25,40).

El imperativo del amor al prójimo no constituye una propaganda publicitaria para las religiones, él nace de la experiencia del amor que Dios ha tenido por nosotros, de la presencia de su Espíritu que nos impulsa a amar como Dios no ha amado. Por ello, la religión que dice que ama a Dios, pero no ama al hermano es una mentira, un engaño, una negación de lo que pretende afirmar: "Cómo puede amar a Dios, a quien no ve, si no es capaz de amar al hermano, a quien ve?" (1 Jn 4,20). Esto que al menos en teoría es tan evidente para la tradición judeo-cristiana, también constituye un imperativo de la religión islámica: “La piedad verdadera no consiste en volver el rostro hacia el este o hacia el oeste; piadoso, en verdad, es quien cree en Dios, en el Último Día, en los ángeles, en la revelación, en los profetas; y gasta de lo que tiene - a pesar de su apego a ello- en sus parientes, en los huérfanos, los necesitados, los viajeros, los mendigos" (Sura 2, Al-Baqara,177).

Este nexo profundo que existe entre amor a Dios y al prójimo, es el que nos permite pensarnos como auténtica comunidad humana. Como lo expresa el Vaticano II en su Declaración sobre las relaciones de la Iglesia con las religiones no cristianas, "Todos los pueblos forman una comunidad, tienen un mismo origen, puesto que Dios hizo habitar a todo el género humano sobre la faz de la tierra, y tienen también un fin último, que es Dios, cuya providencia, manifestación de bondad y designios de salvación se extienden a todos, hasta que se unan los elegidos en la ciudad santa, que será iluminada por el resplandor de Dios y en la que los pueblos caminarán bajo su luz" (NA 1). La salvación no es asunto privado, 
sino universal. Es el mismo y único Dios el que se ha manifestado a todos los pueblos, lo ha hecho de diversos modos -según los pueblos y culturas lo hayan podido reconocer, y nos ha querido a todos formando una sola comunidad. La Iglesia católica tiene al respecto una misión ineludible, por supuesto que compartida por otras comunidades religiosas: "ser signo e instrumento de la comunión de los hombres entre sí y de la comunión de todo el genero humano" (LG 1). Las religiones, en sus legítimas diferencias - queridas por Dios, según NAestán todas llamadas a contribuir a esta comunión, "a entrar - como ha invitado el Papa Francisco - en un diálogo entre ellas orientado al cuidado de la naturaleza, a la defensa de los pobres, a la construcción de redes de respeto y de fraternidad" (LS 200).

Así como el reconocimiento de la dimensión religiosa de la vida no lleva a un desprecio del hombre, consecuentemente, cuando la vida es reconocida de cara a Dios, entonces ella es también afirmación de esta casa común que se nos ha regalado para habitar, compartir y cuidar (Gn 2,15). Como lo ha expresado el Papa Francisco, es importante reconocer "la riqueza que las religiones pueden ofrecer para una ecología integral y para un desarrollo pleno de la humanidad" (LS 62).

\section{EL INTERÉS ESTRATÉGICO DE LA RELIGIÓN}

No se debe identificar, sin más, la institucionalidad de las religiones con el "espíritu religioso", con el "sentido espiritual en la vida humana". Nuestra cultura, en gran parte con razón, tiene muchos reparos con las instituciones y con las instituciones religiosas en particular. Esto no es sólo un fenómeno chileno, sino que mundial. El fundamentalismo religioso, desgraciadamente no conoce religiones ni fronteras, baste ver los movimientos fundamentalistas cristianos en USA, por ejemplo; o los movimientos fundamentalistas islámicos en Oriente y Europa (Aldona Maria Piwko, 2021; Cf. Blume, 2016; Breul, 2019; Goldstein, 2021; Klein, 2017; Ludwig, 2014; cf Verweyen, 1996). Una religión pura, 
inmaculada, no existe. De allí la necesaria vigilancia respecto de ella: desde ella, pero también, con legítimo derecho de la sociedad sobre ella.

Es necesario distinguir la religión de los usos que de ella se hace en función de intereses ajenos a ella, como pudieran ser la pobreza de los pobres, el exterminio de grupos y razas, la destrucción del planeta, o cuando la religión se pone al servicio de intereses más individuales y pedestres: el dinero, el prestigio, el sexo, entre otros. Pero la necesaria distinción entre intereses religiosos e intereses espurios, no debe llevar a la negación del carácter histórico-institucional de las religiones. El sentido religioso o espiritual debe cultivarse a fin de que florezca, no se marchite o viva gravemente enfermo. La institucionalidad debe ayudar, no impedir. Por ello, la salud de las instituciones religiosas resulta ser de un interés estratégico fundamental para la sociedad. En este sentido, se hace necesario que el Estado, en lugar de desentenderse de las religiones, les de espacio para un sano desarrollo moral, intelectual y moral. La educación religiosa de las personas no es baladí. A través de ella, los niños y jóvenes pueden llegar a saber - en palabras de la gran educadora de Chile, Gabriela Mistral- que "la montaña es más que una montaña", a reconocer sus preguntas más fundamentales, a conocer y discernir las diversas respuestas a esas preguntas, a convivir en paz y fraternidad con quienes no creen del modo que ellos lo hacen, a comprender cómo la afirmación de Dios comporta siempre una afirmación inalienable de la persona humana, a valorar las diferentes culturas y sus experiencias de lo sagrado, de lo santo, de lo trascendente. Por cierto, esta educación compete a las religiones; sin embargo, por la importancia que esa formación espiritual representa para las personas, se constituye también en una tarea que el Estado debe fomentar y asegurar. Como ha afirmado Hans Küng, para comprender "la actual situación del mundo, hoy en día hay que ser competente no sólo en materia de economía, cultura y sociedad sino también en materia de religión" (Küng, 2013, pp. 5-6).

Nuestra convicción es que la cultura se beneficia de las religiones. Sin embargo, pensamos también que dicha convicción se debe complementar con esta otra: las religiones 
se benefician de la cultura. Como se dice en el no 1 de Gaudium et spes, "la Iglesia católica se siente íntima y realmente solidaria del genero humano y de su historia". Y no puede ser de otra manera, las religiones no existen al margen de la cultura, sino que son también ellas mismas parte viva de las culturas. Por ello, el Vaticano II afirma que "la Iglesia necesita de modo muy peculiar la ayuda de quienes por vivir en el mundo, sean o no sean creyentes, conocen a fondo las diversas instituciones y disciplinas y comprenden con claridad la razón íntima de todas ellas. Es propio de todo el Pueblo de Dios, pero principalmente de los pastores y de los teólogos, auscultar, discernir e interpretar, con la ayuda del Espíritu Santo, las múltiples voces de nuestro tiempo y valorarlas a la luz de la palabra divina, a fin de que la Verdad revelada pueda ser mejor percibida, mejor entendida y expresada en forma más adecuada". Muchas cosas se pudieran decir de este importante texto; pero, quiero destacar su tono general: la valoración teológica de la historia, de la acción que en ella realizan tanto creyentes, como no creyentes. La historia, la cultura, las "múltiples voces de nuestro tiempo" nos pueden ayudar a comprender y a vivir más plenamente la verdad. Por tanto, no hay lugar para una enemistad con la cultura de nuestro tiempo. La necesitamos no de modo instrumental, para algo, para una mejor evangelización, por ejemplo. La necesitamos porque es nuestro espacio vital, nuestro mundo, el espacio que Dios ha querido crear y redimir.

\section{PARA CONCLUIR}

En un momento crítico de la historia de Chile, en Septiembre del año 1974, el Cardenal Silva Henríquez, en el Te Deum celebrado en la catedral de Santiago, proponía "nuestra más urgente tarea: reencontrar el consenso; más que eso, consolidar la comunión en aquellos valores espirituales que crearon la patria en su origen. La historia demuestra y seguirá demostrando- que sólo en esta fidelidad es fecunda la esperanza" (Silva Henríquez, 1974). Pareciera pertinente que en este proceso constituyente volviéramos a reconocer la necesidad de reencuentro en nuestros más profundos valores espirituales. "Los pueblos que enajenan su tradición y por manía imitativa, violencia impositiva o imperdonable 
negligencia o apatía toleran que se les arrebate el alma - advertía el Cardenal Silva-, pierden, junto con su fisonomía espiritual, su consistencia moral y finalmente su independencia ideológica, económica y política" (Silva Henríquez, 1974). Ciertamente, “el alma de Chile" no es una cosa que esté allí para ser observada y claramente descrita. Tampoco el "alma de Chile" está constituída por un conjunto inmutable de principios, valores e ideas, a los que fácilmente podemos recurrir y encontrar en ellos ese anhelado consenso. Sin embargo, tendríamos que estar al menos de acuerdo en que Chile es más que una suma de individuos luchando por producir, consumir y subsistir, en un espacio geográfico determinado.

La tradición judeo-cristiana nos ayuda a recordar que "No solo de pan vivirá el hombre" (Dt 8,3 Lc 4,4). ¿Qué significa esta advertencia? Nuestra existencia se empobrece, se embrutece, cuando no es capaz de conectarse con las letras, las artes, la religión. El espíritu humano es indisociable de la materia, pero no se agota en ella. El espíritu es aquello que nos permite superar la mera contingencia, las determinaciones y condicionamientos de nuestra vida. El espíritu humano busca al Espíritu, a ese aliento de vida que está en toda criatura, esa fuerza que le permite ser en libertad.

Una Constitución no sólo debiera reconocer el sentido religioso de la vida humana, sino que también generar las condiciones estructurales para su desarrollo. Con ello se enriquece la misma sociedad, los hombres y mujeres que habitan la patria no quedan reducidos a relaciones meramente económicas, políticas y funcionales, sino que son reconocidos como personas que han nacido del amor de Dios y que han sido invitadas a vivir en una fraternidad que supera todo tipo de segregación, a vivir en una comunidad reconciliada, como la que anunciaba el Apóstol Pablo: "ya no hay judío ni gentil", porque la condición religiosa no se establece como privilegio de salvación; "ya no hay hombre ni mujer", porque cualquiera sea la condición sexual estamos tod@s Ilamad@s a participar de la vida común; "ya no hay esclavo ni libre", porque una auténtica comunidad supera también cualquier segregación social, económica o política (Cf. Gál 3,28). Por cierto, las religiones - 
y con propiedad puedo decirlo del cristianismo - no siempre han estado a la altura de su vocación. Pero, como tampoco lo han estado otras instituciones de la sociedad. Las claudicaciones de las religiones no justifican su desconocimiento y exclusión. Parte de la verdad histórica es reconocer también los aportes sustantivos que las religiones hacen a la vida, al desarrollo de los pueblos y culturas.

Necesitamos reencontrarnos, necesitamos reconocernos como comunidad nacional (o plurinacional). Y, para ello, nos puede ayudar volver a nuestras raíces y desde ellas nutrir nuestra creatividad, recrear nuestra identidad y volvernos a encontrar. Las diversas tradiciones religiosas y todas las corrientes espirituales que hacen posible nuestra vida común tienen un aporte sustantivo que hacer en este proceso. Ninguna religión, ninguna espiritualidad, ningún sistema de creencias tiene mejores derechos en la regeneración del alma de nuestra Patria. Tampoco sumaría a este diálogo ciudadano la soberbia de quienes piensan estar en superioridad moral, intelectual o espiritual, respecto de otras personas o grupos de la sociedad. La nueva Constitución puede llegar a ser un símbolo del alma de la patria que nace desde las raíces del tiempo y que se proyecta con esperanzas a ese futuro que es siempre nuevo y que demanda del aporte creativo de todos, también de las religiones.

\section{BIBLIOGRAFÍA}

- Aldona Maria Piwko. (2021). Islamic fundamentalism: From ideologists to propaganda in the mass media of terrorist groups. Journal for the Study of Religions and Ideologies, 20(58), 175-192.

- $\quad$ Blume, M. 1976-. (2016). Religiöser Fundamentalismus \& Extremismus: Die gefährlichen Seiten des Glaubens (2. Auflage). sciebooks Verlag.

- $\quad$ Breul, M. 1986-. (2019). Was haben Donald Trump und ein religiöser Fundamentalist gemeinsam?: Die erstaunlichen Parallelen zwischen religiösem Fundamentalismus und postfaktischem Populismus fordern auch die Religionsgemeinschaften heraus. Denken 
und glauben, 191, 4 .

- Enders, M. (2007). Ist der Mensch von Natur aus religiös?: Zum Verständnis des Menschen aus der Sicht christlicher Religionsphilosophie. Jahrbuch für Religionsphilosophie, 6, 37-68.

- Goldstein, W. S. (2021). Trump, the religious right, and the spectre of fascism. Critical Research on Religion, 9(1), 3-7.

- Grondin, J. (2005). El sentido de la vida. Un ensayo filosófico. Herder.

- Grondin, J. (2010). Filosofía de la religión. Herder.

- Klein, C. (2017). Religiöser Fundamentalismus: Merkmale, Konzepte, Messinstrumente und Korrelate. Religiosität: die dunkle Seite, 139.

- $\quad$ Küng, H. (2013). En busca de nuestras huellas. La dimensión espiritual de las religiones del mundo. Debolsillo.

- Ludwig, C. (2014). Dimensionen des religiösen Fundamentalismus in der säkularen Moderne. Sozialformen der Religionen im Wandel, 81.

- Mistral, G. (2020). Toda culpa es un misterio. Antología mística y religiosa de Gabriela Mistral (D. Del Pozo, Ed.). La Pollera Ediciones.

- Rahner, K. (1989). Curso fundamental sobre la fe. Introducción al concepto de cristianismo (Vol. 4). Herder.

- Silva Henríquez, R. (1974). La Iglesia y la Patria. Homilia en el Te Deum Ecuménico. http://www.cardenalsilva.cl/pdf/43_iglesia.pdf

- Skorka, A. (2006). El concepto de «Ruah Hakodesh» en las fuentes judías y su relación con el cristianismo. Revista Teología, XLII(91), 479-487.

- $\quad$ Tillich, P. (1973). Filosofía de la religión. La Aurora.

- Tillich, P. (1982). Teología sistemática. I, La razón y la revelación, el ser y Dios (3a. ed). Sígueme.

- Verweyen, H. (1996). Pluralismus als Fundamentalismusverstärker? En R. Schwager (Ed.), Christus allein? Der Streit um die pluralistiche Religionstheologie (Vol. 1-Book, Section, pp. 132-157). Herder.

- Welte, B. (1973). El hombre entre lo finito y lo infinito. Guadalupe. 
Joaquín Silva Soler: El sentido religioso de la vida

- Welte, B. (1982). Filosofía de la religión. Herder. 